\title{
Progress in developing a structure- activity-relationship for the direct aromatization of methane
}

\author{
Ina Vollmer ${ }^{1}$, Irina Yarulina ${ }^{2}$, Freek Kapteijn ${ }^{1}$ and Jorge Gascon ${ }^{1,2}$ \\ ${ }^{1}$ Catalysis Engineering, Chemical Engineering Department Delft University of Technology, \\ Van der Maasweg 9, 2629 HZ Delft, The Netherlands. \\ ${ }^{2}$ King Abdullah University of Science and Technology, KAUST Catalysis Center, Advanced \\ Catalytic Materials, Thuwal 23955, Saudi Arabia \\ ${ }^{*}$ Correspondence to: jorge.gascon@kaust.edu.sa
}

\begin{abstract}
To secure future supply of aromatics, methane is a commercially interesting alternative feedstock. Direct conversion of methane into aromatics combines the challenge of activating one of the strongest $\mathrm{C}-\mathrm{H}$ bonds in all hydrocarbons with the selective aromatization over zeolites. To address these challenges, smart catalyst and process design are a must. And for that, understanding the most important factors leading to successful methane $\mathrm{C}-\mathrm{H}$ bond activation and selective aromatization is needed. In this review, we summarize mechanistic insight that has been gained so far not only for this reaction, but also for other similar processes involving aromatization reactions over zeolites. With that, we highlight what can be learnt from similar processes. In addition, we provide an overview of characterization tools and strategies, which are useful to gain structural information about this particular metalzeolite system at reaction conditions. Here we also aim to inspire future characterization work, by giving an outlook on characterization strategies that have not yet been applied for the methane dehydroaromatization catalyst, but are promising for this system.
\end{abstract}

\section{Introduction}

As the main building block of polystyrene and numerous consumer goods, such as pharmaceuticals, aromatics are essential to modern life. At the moment the main source of benzene, toluene and xylene (BTX) is steam-reforming of naphtha, but especially in North America naphtha is more and more replaced by shale gas liquids as a cheaper cracking feedstock for olefin production and this process does not yield aromatics. ${ }^{[1]}$ There is high interest in using methane as an alternative feedstock to produce aromatics, because of its high availability from shale gas and clathrates. ${ }^{[2]}$ Methane is an attractive feedstock also because $3.5 \%$ of the global production of natural gas is currently flared as a by-product of crude oil facilities, because it cannot be utilized on-site due to a lack of convenient technology that is applicable on a small scale. ${ }^{[3]}$ This represents a great economic opportunity. Utilizing instead of burning flare gas has the added environmental benefit of avoiding $\mathrm{CO}_{2}$ emissions. Methane however is hard to activate and is currently used mostly as 
an energy source, because of its high $\mathrm{C}-\mathrm{H}$ bond energy of $104 \mathrm{kcal} / \mathrm{mol} .{ }^{[4]}$ Indirect valorization of methane is possible via the syngas route, but requires many process steps. The direct aromatization of methane without addition of oxidants has gained interest since it was shown to be feasible first by Bragin and later Wang et al. ${ }^{[5,6]}$ It presents an alternative to the indirect valorization of methane via the syngas route, potentially applicable on a smaller scale and overall advantageous since it requires less process steps. Many challenges need to be overcome before this process can be commercialized. The reaction of methane to benzene and hydrogen is hampered by thermodynamics with $\Delta G_{r}^{o}=+104 \mathrm{kcal} \mathrm{mol}^{-1}$ and $\Delta H_{r}^{0}=+127 \mathrm{kcal} \mathrm{mol}^{-1}$.77-9] At the temperatures at which this reaction produces interesting yields of benzene $(7.8-21.5 \mathrm{~mol} \%)$, typically between 650 and $800{ }^{\circ} \mathrm{C}$, coke formation experiences no such thermodynamic limitations leading to fast deactivation of the catalyst. ${ }^{[7,8]}$ Mo/HZSM-5, molybdenum (Mo) supported on an MFI zeolite remains the most investigated Methane Dehydroaromatization (MDA) catalyst to date, because of its superior performance. ${ }^{[10,11]}$ Both different metals ${ }^{[12,13]}$ and other supports ${ }^{[14]}$ have not yielded improvements over this system. More insight into the mechanism and into the exact role and function of the metal active site are key to further improve this catalyst.

The many possible reaction mechanisms proposed for MDA have not yet converged to a common agreement. ${ }^{[5,6]}$ The number of pathways to consider is similarly unwieldy as in other reactions involving zeolites like the $\mathrm{M} 2$ process (aromatization of light hydrocarbons) and fluid catalytic cracking. ${ }^{[15,16]}$ Similarities can also be expected with the Methanol to Hydrocarbons (MTH) process, for which a hydrocarbon pool mechanism is widely accepted. ${ }^{[17-26]}$ Indeed a hydrocarbon pool was recently also proposed to play a crucial role in MDA, although it was suggested to proceed via aromatic radicals instead of carbocations. ${ }^{[27]}$ A series of dehydrogenation, cracking, isomerization, oligomerization, dehydrocyclization, $\beta$ scission, protolysis and hydride transfer reactions has to be considered. ${ }^{[28]}$ Karakaya et al. in one of the few attempts to try to model this complex reaction network used 50 reaction steps and these did not even include pathways to carbonaceous deposits. ${ }^{[29]}$ Kinetic modelling is also complicated by the fact that steady state conditions are never really reached during MDA, because of fast coking.

There is some consensus however, that the process has an activation period and proceeds via a two-step mechanism. A few transition metals are active for MDA, of which Mo was reported to be the most active. ${ }^{[12,13]}$ Mo species transform to an active phase during an initial period of the reaction where no desired products are observed. ${ }^{[30-35],[36]}$ The structure of this reduced active site is not yet fully revealed. Because the active phase of Mo forms at reaction conditions, characterization of the sites present and identification of the sites responsible for catalysis is difficult. A lot of publications agree that once the active site is formed, the reaction proceeds via a two-step mechanism on the bifunctional catalyst Mo/HZSM-5. ${ }^{[36-39]}$ According to this two-step mechanism methane is first activated on the Mo active site to form C2 intermediates (ethane, ethylene or acetylene) which are then further dehydrocyclized to benzene and other aromatics on the Brønsted acid sites (BASs) of the zeolite. In the first part of this review, we will summarize the potential structures of the active site along with characterization techniques and strategies that can be applied to better understand this system at reaction conditions. In this part, we will also discuss proposed mechanisms for the $\mathrm{C}-\mathrm{H}$ bond activation of methane on the active site.

The second part of the review focusses on the reaction steps following methane activation. The most mentioned intermediates are ethylene and acetylene. Therefore, this part of the 
review is devoted to aromatization reactions of these two hydrocarbons and compares what has been reported for these reactions with observations about MDA. The catalytic role of the BAS on the catalyst will be at the center of this discussion. To summarize this part, we will discuss the two-step mechanism as a proposed reaction mechanism and address the question of whether it is possible to separate the two functions of the bifunctional catalyst.

\section{Metal active site}

Activation of methane is achieved over a transition metal supported on a zeolite, where the transition metal ion (TMI) anchors to the framework Al through oxygen, replacing the proton of the BAS.

The BAS itself can only very slowly activate methane, which was shown by feeding methane to bare $\mathrm{HZSM}-5^{[40,41]}$ and by $\mathrm{CD}_{4}$ exchange with $\mathrm{HZSM}-5$ to form $\mathrm{CD}_{3} \mathrm{H} .{ }^{[42]}$ Although the exchange of $\mathrm{OH}$ with $\mathrm{D}_{2}$ was shown to be enhanced when Mo is present on HZSM-5, this activation still happens far too slow to play a major role in the mechanism of methane $\mathrm{C}-\mathrm{H}$ bond activation. ${ }^{[43]}$ To understand how methane interacts with the metal active site during activation, knowledge about the structure, nuclearity and oxidation state of the active site is crucial.

\section{Understanding the structure of the metal site}

Table 1: Overview of transition metal ions supported on ZSM-5 used as a catalyst for MDA and their reported active phase.

\begin{tabular}{|c|c|c|}
\hline Cation & Proposed active phase & \\
\hline Mo & $\begin{array}{l}\mathrm{MoC}, \mathrm{Mo}_{2} \mathrm{C} \text {, coke modified } \mathrm{Mo}_{2} \mathrm{C}^{[44]}, \mathrm{Mo}_{2} \mathrm{C}^{[32,} \\
45] \text { on the outer surface and reduced oxides in } \\
\text { the pores of the zeolite, any kind of } \mathrm{Mo}^{6+} \text { and } \\
\text { partially reduced } \mathrm{Mo}^{6+} \text { as } \mathrm{MoO}_{(3-x) \cdot}{ }^{[46,47]}\end{array}$ & Two-step mechanism ${ }^{[36-39]}$ \\
\hline W & $\begin{array}{l}\text { Reduced with evolution of } \mathrm{CO}, \mathrm{CO}_{2} \text { and } \mathrm{H}_{2} \mathrm{O} \\
\text { during activation }{ }^{[13]}\end{array}$ & \\
\hline $\mathrm{Fe}$ & $\begin{array}{l}\text { Reduced with evolution of } \mathrm{CO}, \mathrm{CO}_{2} \text { and } \mathrm{H}_{2} \mathrm{O} \\
\text { during activation }{ }^{[13]} \text {, carbide }{ }^{[48]}\end{array}$ & \\
\hline V & $\begin{array}{l}\text { Reduced with evolution of } \mathrm{CO}, \mathrm{CO}_{2} \text { and } \mathrm{H}_{2} \mathrm{O} \\
\text { during activation }{ }^{[13]}\end{array}$ & \\
\hline $\mathrm{Cr}$ & $\begin{array}{l}\text { Reduced with evolution of } \mathrm{CO}, \mathrm{CO}_{2} \text { and } \mathrm{H}_{2} \mathrm{O} \\
\text { during activation }\end{array}$ & \\
\hline $\mathbf{R e}$ & $\begin{array}{l}\text { Metallic Re forming with evolution of } \mathrm{CO}, \mathrm{CO}_{2} \\
\text { and } \mathrm{H}_{2} \mathrm{O}^{[49]}\end{array}$ & \\
\hline Mn & Carbide $e^{[50]}$ & \\
\hline Zn & $\mathrm{Zn}^{2+}, \mathrm{Nano}-\mathrm{ZnO} \mathrm{O}^{[51-55]}$ & $\begin{array}{l}\text { Methoxy species pathway, } \\
\text { where } \mathrm{H} \text { is abstracted by } \\
\mathrm{Zn}^{[51-55]}\end{array}$ \\
\hline $\mathrm{Ag}^{\mathrm{b}}$ & $\mathrm{Ag}^{+[51,56,57]}$ & $\begin{array}{l}\text { Methoxy species pathway, } \\
\text { where } \mathrm{H} \text { is abstracted by } \\
\mathrm{Ag}^{[51,56,57]}\end{array}$ \\
\hline $\ln ^{a}$ & $\operatorname{lnO}+[58]$ & $\begin{array}{l}\text { Methoxy species pathway, } \\
\text { where } \mathrm{H} \text { is abstracted by } \ln ^{[58]}\end{array}$ \\
\hline
\end{tabular}

${ }^{a}$ Conversion of $\mathrm{CH}_{4}$ is only observed in the presence of ethylene

${ }^{b}$ significant conversion of $\mathrm{CH}_{4}$ is only observed in the presence of ethylene or ethane 
Several TMls are reported to be active for MDA. These TMls, summarized in Table 1, can be separated into two categories: The first category comprises Mo, W, Fe, V, Cr, Re and Mn, which experience an activation period during which the TMI is reduced and most likely carburized to its active phase; for the second category, made up of $\mathrm{Zn}$, In and Ag the active phase is reported to be a cation acting as a proton abstraction site. It has to be noted however that $\mathrm{Ag}$ and In were only reported to convert methane in the presence of ethylene. The most investigated metal for MDA is Mo, because of its superior activity, while almost no structural characterization is reported for other metals showing activity for MDA. ${ }^{[13]}$ We will therefore focus on Mo specifically in the following although similar trends can also be expected for the other TMls in the first category. Mo is present as an oxide on the assynthesized catalyst. This catalyst pre-cursor has received much research attention, which was reviewed earlier. ${ }^{[10,11,59-64]}$ The as-synthesized oxidic Mo was shown to reduce to its active form in an initial period of the reaction where no gaseous hydrocarbons are formed yet. ${ }^{[30-35] ~[36]}$ It is poorly understood how the Mo precursor state influences the state of Mo at reaction conditions. ${ }^{[65]}$ It is for instance conceivable that the Mo loses its ability to anchor to the zeolite framework, when it is being reduced. ${ }^{[66,67]}$ It is however commonly agreed that a better initial Mo dispersion leads to a more stable catalyst producing higher yields of benzene and naphthalene. ${ }^{[68]}$ Therefore, the state of the catalyst pre-cursor has at least some influence on the active, reduced Mo phase formed at reaction conditions. For example, the Mo pre-cursor state can have an influence on its reducibility and its propensity to cluster or even form nanoparticles at reaction conditions.

The information listed below is needed to fully characterize the active site and to build up structure-activity relationships:

- Metal-support interaction: does the Mo detach from the zeolite during activation?

- Dispersion

- Location

- Nuclearity

- Stoichiometry (including heteroatoms)

- Geometry

- Charge

But characterizing the metal-zeolite system for MDA is highly challenging: 1) The metal precursor takes on numerous configurations when supported on the zeolite, which leads to complicated and broadened signals for most spectroscopic techniques. 2) It is not the assynthesized catalyst that is active, but the active site forms at reaction conditions, thus necessitating operando characterization techniques. 3) The characterization is further complicated by heavy coking in all stages of activation of the catalyst and during the reaction. 4) Not only the metal in the pre-catalyst can adopt different configurations, it is also not clear whether all the TMI transform to active sites and it is therefore difficult to distinguish between spectators and active sites. These aspects have hampered elucidation of the exact structure of the active sites present on the catalyst for MDA and understanding about which of the many possible structures are responsible for catalysis. The first three of these complications are addressed below with ways to circumvent them and obtain information regarding the aspects listed above. 


\section{1) Inhomogeneity}

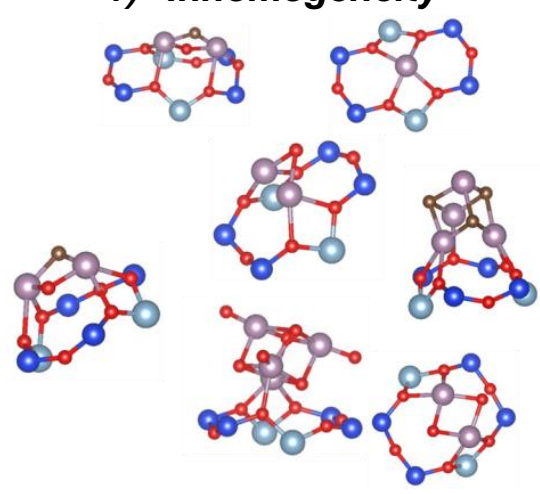

Figure 1: Various possible structures of (oxy-)carbidic Mo sites anchored on the HZSM-5 zeolite. Colors correspond to Mo (purple), Si (blue), Al (turquoise), O (red) and C (brown).

This part aims to highlight the characterization difficulties that stem from the fact that Mo is present in varying nuclearity, oxidation state and geometry and how to overcome those challenges. The Mo/HZSM-5 system is compared to two well-known types of catalysts, the supported nanoparticle catalyst and the supported metal-organic catalyst to show that it belongs to neither category, but that inspiration for characterization techniques can be drawn especially from the latter category. Here we make a distinction between Mo species anchored to the zeolite inside the pores and bigger Mo species on the outer surface of the zeolite particles. The anchoring of Mo to the zeolite framework leads to different possible geometries and complicates spectroscopic characterization. The presence of bigger Mo species on the outer surface perturbs the signal for bulk characterization techniques. We discuss ways to address these two issues and provide a summary of techniques that can be applied to avoid bigger Mo clusters during the synthesis.

For a long time, the classical view of a heterogeneous catalyst involved an oxide support with nanoparticles of the active metal. ${ }^{[69,70]}$ The other extreme is a well-defined, usually monomeric immobilized organometallic complex. ${ }^{[71-74]}$ On zeolite supports, both bigger metal clusters and even nanoparticles ${ }^{[66]}$ as well as mono- ${ }^{[67]}$ or dimeric ${ }^{[75]}$ sites coexist (see Figure 1 for some examples). In recent years, a lot of work has moved towards single-site catalysts. ${ }^{[76]}$ For MDA, this is reflected by the fact that reported metal loadings decreased over the years. Early studies reported metal loadings up to $10 \mathrm{wt} . \%$, which represents a molar metal/Al ratio far above one, meaning that a large part of the metal cannot effectively be anchored to the zeolite and has to be present as bigger clusters. This represents the classical view of a nanoparticle supported on a support, where BAS were not yet valued for their anchoring role, but solely as an active site for the aromatization reactions. Later studies found that a loading of around 2 to 4 wt.\%, depending on the Al content of the zeolite shows the highest activity per metal atom while most of the coke is formed on bulk Mo oxide, aluminium molybdate and other extra-framework species. ${ }^{[36,37,77-79]}$ The metal to Al ratio at which anchoring to the framework $\mathrm{Al}$ is still effective seems to be far below one for most zeolites. The anchoring capacity of the zeolite has been investigated mostly for the oxidic catalyst pre-cursor. By combining XPS, TPO and UV Raman, Lim et al. showed that the amount of bulk surface Mo oxide species decreases with decreasing the Si/Al ratio thereby increasing the BAS density, Mo dispersion being proportional to the amount of BAS. ${ }^{[77,80]}$ Consequently, the highest benzene formation and the lowest deactivation rates were obtained over the catalyst with the highest amount of acid sites. 
In some sense, the metal-zeolite system is comparable to e.g. an organometallic complex grafted on silica, where silanol $\mathrm{OH}$ groups serve as the anchor, while an acidic $\mathrm{OH}$ group serves this purpose on a zeolite. ${ }^{[81]}$ Many studies suggest that only the Mo species anchored to the framework Al through oxygen bridges are actually able to activate methane. ${ }^{[27,67,81]}$ This is consistent with what has been proposed for the methane to methanol reaction ${ }^{[82,83]}$ and for SCR of $\mathrm{N}_{2} \mathrm{O} \cdot{ }^{[84]}$

Part of the metal is present as well-defined species and for those species some characterization techniques useful for supported organometallic compounds can be insightful for the metal on HZSM-5 system as well. ${ }^{[71,85]}$ Both CO FTIR and ${ }^{13} \mathrm{C}$ MAS NMR are often used to characterize metal-organics supported on silica. CO FTIR can distinguish between mono- or dimeric and species and bigger clusters. CO adsorbs only on the reduced Mo species after activation. ${ }^{[86,87]}$ With FTIR distinct vibrations for different Mo sites present in the zeolite can be observed after activation of those sites has been completed. ${ }^{[88,89]}$ Using this technique combined with theory, information about the oxidation state as well as nuclearity of the reduced Mo can be gained for this system. ${ }^{[87]}$ The chemical shift of ${ }^{13} \mathrm{C}$ MAS NMR and its anisotropy can yield information about carbidic Mo species forming at reaction conditions, but often the signal is dominated by a big contribution from carbonaceous deposits. ${ }^{\text {[90-93] } \mathrm{We}}$ recently demonstrated that $\mathrm{CO}$ pretreatment results in an active site equivalent to the one formed at reaction conditions, but without the presence of any carbonaceous deposits. ${ }^{\text {[4] }}$ High resolution ${ }^{13} \mathrm{C}$ MAS NMR then revealed three different carbidic resonances: a sharp one stemming from $\mathrm{Mo}_{2} \mathrm{C}$ nanoparticles on the outer surface of the zeolite and two broad resonances corresponding to smaller species inside the pores of the zeolite. However, the interpretation of the spectra obtained for metal-zeolite systems compared to the ones obtained for supported metalorganics is much more complicated. This is because, in contrast to the metalorganic system, for Mo/HZSM-5 the anchoring zeolite $\mathrm{OH}$ groups are not uniform, but in different local geometries depending on the location of the framework Al inside the pores and cages of the material. It is likely that the confinement effect of the zeolite also stabilizes mono- and dimeric species at the $\mathrm{OH}$-groups inside the porous structure of the zeolite. ${ }^{[85]}$ Because of this, they can direct the cation to take on many different geometries. ${ }^{[65]}$ This complicates characterization further, because it leads to rather broad contributions for spectroscopic techniques that probe the metal directly like EPR, ${ }^{[95,}{ }^{96]}{ }^{95} \mathrm{Mo} \mathrm{NMR},{ }^{[97]} \mathrm{UV}-\mathrm{Vis},{ }^{[67}$, ${ }^{68,98]}$ XAS, $^{[99]}$ UV-Raman ${ }^{[80,100]}$ and XPS ${ }^{[7,101]}$.

In addition, synthesis of a zeolite catalyst with perfect dispersion of the metal is still a challenge, and bigger clusters, especially at the external surface of the zeolite, are almost always present. They often dominate the signal in bulk spectroscopic techniques. Therefore, a way to avoid bigger clusters on the external surface could lead to a lot of insight about the active site. Silanation of the external BASs of the zeolite prior to Mo incorporation is one way to mitigate their formation. ${ }^{[102]}$ This was found to increase the selectivity to products and slow down coking. For other metals, using chemical vapor deposition (CVD) techniques or cation exchange to incorporate the metal leads to better dispersion compared to the predominantly used solid ion exchange (SIE) and Incipient Wetness Impregnation (IWI). ${ }^{[5,103]}$ CVD was performed for MDA using $\mathrm{WCl}_{6}$, but it is not known, if this improved the dispersion of the metal, because the catalyst synthesized this way was not compared to a catalyst prepared with the conventional method of IWI. ${ }^{[75]}$ For zeolites with bigger cages, $\mathrm{Mo}(\mathrm{CO})_{6}$ is often incorporated into the zeolite through CVD. ${ }^{[104,105]}$ Regulating $\mathrm{pH}$ of the solution for impregnation ${ }^{[106,107]}$ or changing the atmosphere during calcination also influences metal dispersion. ${ }^{[108]}$ A couple of indirect methods are available to characterize the dispersion of the 
metal, probing how many acid sites are replaced by a metal. This was effectively achieved by $\mathrm{H} / \mathrm{D}$ exchange,${ }^{[43,75,81]}{ }^{1} \mathrm{H}$ NMR, ${ }^{[27,109]}{ }^{27} \mathrm{Al} \mathrm{NMR},{ }^{[109-111]} \mathrm{NH}_{3}-\mathrm{TPD}^{[52,77,112,113]}$ and probing adsorbed molecules by FTIR ${ }^{[40,114]}$. $\mathrm{CH}_{4}-\mathrm{TPR}^{[115]}$ and $\mathrm{H}_{2}$-TPR ${ }^{[116]}$ were also used to study the ease of reduction of the Mo species present on the zeolite. Reduction at lower temperatures is an indication of the presence of big Mo oxide clusters on the outer surface of the zeolite. Dispersion of Mo seems to be the most important factor for an active catalyst. A catalyst with Mo present only as mono- and dimeric species that do not cluster at reaction conditions has not been synthesized yet.

Understanding which sites are present on the catalyst is challenging, firstly because nanoparticles on the outer surface of the zeolite dominate the signal in bulk characterization techniques, and secondly because even the species in the pores of the zeolite can take on different geometries and nuclearities. It is clear that many sites coexist on the (pre-)catalyst and it is likely that only a fraction of them is actually responsible for all the catalysis. ${ }^{[72,117]}$

\section{2) Operando is key}

The as-synthesized oxidic Mo was shown to reduce to its active form in an initial period of the reaction where no gaseous hydrocarbon products are formed yet. ${ }^{[30-36]} A$ variety of species have been observed on the catalyst at reaction conditions or after reaction and were proposed as active sites: $\mathrm{MoC}, \mathrm{Mo}_{2} \mathrm{C}$, coke modified $\mathrm{Mo}_{2} \mathrm{C}^{[44]}, \mathrm{Mo}_{2} \mathrm{C}^{[32,45]}$ on the outside surface and reduced oxides in the pores of the zeolite, any kind of $\mathrm{Mo}^{6+}$ and partially reduced $\mathrm{Mo}^{6+}$ as $\mathrm{MoO}_{(3-\mathrm{x})}{ }^{[46,47]}$ Characterizing these carbidic species poses challenges, since many characterization techniques that are powerful in elucidating oxides, like UV-Vis and UVRaman cannot provide information about the reduced species. In addition, since the active species form at reaction conditions, operando characterization is necessary to spot them. It was by operando X-ray Absorption Spectroscopy (XAS) studies that the evolution of the Mo oxidation state during activation was first confirmed. ${ }^{[27,31,94]}$ Another issue relates to the timeresolution. Depending on the Mo loading, the activation period can be rather short. Therefore experiments need to be designed carefully to properly follow the evolution of the active phase. This has been achieved by using a pulsed reaction technique. ${ }^{[27,30]}$ This powerful technique also in combination with quasi-in-situ studies enables the preparation of samples during particular phases of active site formation and allows studying the development of the active site with a variety of techniques. ${ }^{[27,94]}$ Next to XPS, NMR and EPR, FTIR spectroscopy using adsorbed probe molecules can characterize the oxidation state and even nuclearity of the reduced Mo. ${ }^{[27,89,118]}$ In addition to a reduction, the Mo was proposed to also undergo clustering. ${ }^{[67]}$ Bigger Mo clusters were observed on the outer surface of the catalyst after reaction, ${ }^{[6]}$ but it is unclear if this Mo was already present as bigger clusters on the assynthesized catalyst. To observe the clustering operando TEM could be performed. [119] However, zeolite samples are very sensitive to electron beam exposure and low dose imaging techniques are necessary ${ }^{[120,121]}$ not to damage the zeolite for the duration of an MDA experiment. Further, it remains to be determined if bigger Mo clusters also form inside the pores of the zeolite and whether these carbide clusters can activate methane.

\section{3) Coking}

Another factor that complicates elucidation of the metal sites present, is the formation of carbonaceous deposits during the formation of the active site. This makes it difficult to probe the metal-support interaction at reaction conditions and also leads to a darkening of the 
sample, leading to a small signal of vibrational spectroscopy techniques. Knowing whether Mo detaches from the framework Al or stays anchored during initial reduction, limits the number of possible structures one has to consider in reconstructing the geometry of the metal site. On the as-synthesized catalyst, the interaction of the metal with the support can

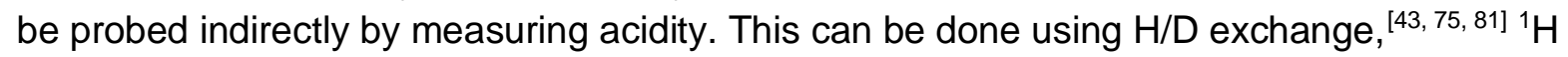
$N M R,{ }^{[122]} \mathrm{Al} \mathrm{NMR},{ }^{[109,110]} \mathrm{NH}_{3}$-TPD ${ }^{[52,77,112,113]}$ and probing adsorbed molecules by FTIR, ${ }^{[40,}$ ${ }^{114]}$ but this is not possible when coke is also responsible for a loss in acidity. One cannot distinguish between a loss of acidity due to carbonaceous deposits and due to a metal replacing the acidic proton. We recently found that the formation of carbonaceous deposits during activation can be avoided using a treatment in $\mathrm{CO}$ to reduce Mo to its active phase. This treatment creates an active site equivalent to the one forming during regular MDA operation. ${ }^{[94]}$ This technique has potential for studying the metal support interaction at reaction conditions without interference from aromatics.

Table 2: Information that can be gained using different spectroscopic techniques and the difficulties encountered using them to characterize the Mo/HZSM-5 system.

\begin{tabular}{|c|c|c|}
\hline $\begin{array}{c}\text { Type of } \\
\text { information }\end{array}$ & Spectroscopic Techniques & Difficulties \\
\hline $\begin{array}{l}\text { Metal-support } \\
\text { interaction: does } \\
\text { the Mo detach } \\
\text { from the zeolite } \\
\text { during activation? }\end{array}$ & \multirow[t]{3}{*}{ 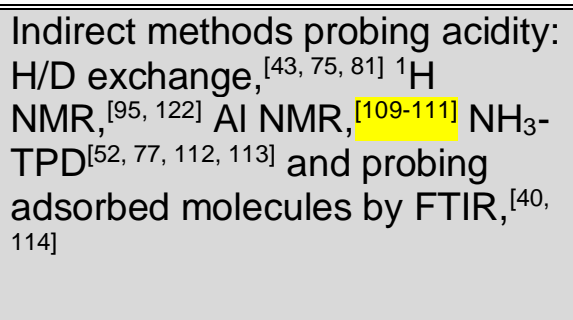 } & \multirow[t]{3}{*}{$\begin{array}{l}\text { Acid sites partly blocked by coke, } \\
\text { which forms together with the } \\
\text { transformation of Mo to its active } \\
\text { phase }\end{array}$} \\
\hline Dispersion & & \\
\hline Location & & \\
\hline \multirow{4}{*}{ Nuclearity } & $\begin{array}{l}\text { UV-Vis } \\
\text { (67, }{ }^{[68,98]} \text { UV-Raman } \\
\end{array}$ & $\begin{array}{l}\text { Difficult to get information on } \\
\text { reduced/carbidic structures }\end{array}$ \\
\hline & ${ }^{13} \mathrm{C}$ NMR & Signal rather broad \\
\hline & $\begin{array}{l}\text { Probing adsorbed molecules by } \\
\text { FTIR }^{[88,89]}\end{array}$ & $\begin{array}{l}\text { Only indirect information from full } \\
\text { width at half maximum and together } \\
\text { with theoretical calculation. Access } \\
\text { can be blocked by coke }\end{array}$ \\
\hline & $\mathrm{H}_{2}-\mathrm{TPR}^{[116]}$ & $\begin{array}{l}\text { Indirect method, nuclearity has to be } \\
\text { inferred from reducibility }\end{array}$ \\
\hline \multirow{3}{*}{ Stoichiometry } & ${ }^{13} \mathrm{C}$ NMR, DNP ${ }^{13} \mathrm{C}$ NMR & Signal rather broad \\
\hline & $\begin{array}{l}\text { Information about removed } \\
\text { oxygen: Temperature } \\
\text { programmed reaction using } \\
\mathrm{CH}_{4}^{[115]}\end{array}$ & $\begin{array}{l}\text { There will not only be carbidic carbon } \\
\text { deposition but also carbonaceous } \\
\text { carbon }\end{array}$ \\
\hline & $\begin{array}{l}\text { Information about deposited } \\
\text { carbon: Temperature } \\
\text { programmed reaction using CO }\end{array}$ & \\
\hline \multirow[b]{2}{*}{ Geometry } & $\mathrm{XANES}^{[31,40,99]}$ & $\begin{array}{l}\text { Bulk technique, only an average over } \\
\text { many structures is observed }\end{array}$ \\
\hline & EXAFS ${ }^{[31,40]}$ & $\begin{array}{l}\text { No long range structure for well } \\
\text { dispersed species, only bulk } \mathrm{Mo}_{2} \mathrm{C} \\
\text { observed }\end{array}$ \\
\hline \multirow[t]{2}{*}{ Charge } & $\mathrm{XANES}^{[30,39,70]}$ & $\begin{array}{l}\text { Bulk technique, only an average over } \\
\text { many structures is observed }\end{array}$ \\
\hline & $\operatorname{EPR}^{[95,96]}$ & $\begin{array}{l}\text { Only information about paramagnetic } \\
\text { species }\end{array}$ \\
\hline
\end{tabular}




\begin{tabular}{|l|l|}
\hline $\mathrm{XPS}^{[7,101]}$ & $\begin{array}{l}\text { Surface sensitive, only information } \\
\text { about the surface is obtained }\end{array}$ \\
\hline $\begin{array}{l}\text { Probing adsorbed molecules by } \\
\text { FTIR }^{[87,123]}\end{array}$ & $\begin{array}{l}\text { Only useful in combination with } \\
\text { references or theoretical calculations }\end{array}$ \\
\hline
\end{tabular}

Table 2 summarizes the key information that is needed to fully characterize the Mo/HZSM-5 at reaction conditions, the characterization techniques that can be applied to obtain this information as well as their limitations. It can be concluded that most of the individual characterization techniques are insufficient to obtain a complete picture, but in combination and also in combination with theoretical calculations they yield a good description.

\section{C-H bond activation}

Various mechanisms by which the metal on the MDA catalyst activates methane are put forward, but uncertainty remains. It is however, crucial to know how the activation proceeds to design a better catalytic systems. One area of debate is whether hydrogen abstraction occurs only on the metal site or with the help of the BAS. It is also not clear whether an adsorbed $\mathrm{CH}_{3}{ }^{+}$species stays adsorbed on the active site and then further reacts with an incoming $\mathrm{CH}_{4}$ or whether a $\mathrm{CH}_{3} \bullet$ radical is released immediately after $\mathrm{H}$ is abstracted and further reaction proceeds in the gas phase. For TMls which form carbidic species at reaction conditions, $\mathrm{CH}_{\mathrm{x}}$ species could also first form through reaction of $\mathrm{H}_{2}$ with the carbidic carbon and then further react with incoming $\mathrm{CH}_{4}$. These possible pathways will be discussed below.

It has been proposed for Ag that the cationic species act as a Lewis acid that is able to abstract hydrogen from methane, while methane forms a methoxy-species with the BAS

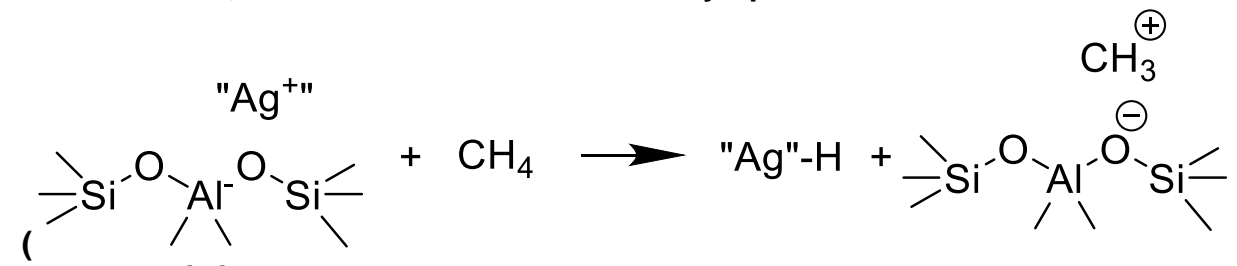

Figure 2). ${ }^{[56]}$<smiles>C[C+](C)O[Si](C)(C)O[Si](C)(C)O[Si](C)(C)O[Si](C)(C)O[Si](C)(C)O[Si](C)(C)C</smiles>

Figure 2: Mechanism of C-H bond activation proposed for Ag/HZSM-5, where the Ag Lewis acid site serves to abstract the proton from $\mathrm{CH}_{4}$. The resulting $\mathrm{CH}_{3}$ forms an alkoxy-species with the oxygen from the BAS. ${ }^{[51]}$

A similar mechanism was proposed for $\mathrm{In}^{[58]}$ and $\mathrm{Zn}^{[52]}$. The work by Kosinov et al. also underlines that both functionalities need to be in close proximity. They discovered that the bifunctional Mo/HZSM-5 cannot be separated into two catalysts, one carrying the Mo functionality and one carrying the BAS. ${ }^{[124]}$ In contrast, for Ta grafted on silica, both $\mathrm{CH}_{3}$ and $\mathrm{H}$ were proposed to coordinate to the metal, where the methyl species then dimerizes when a second $\mathrm{CH}_{4}$ binds to Ta. ${ }^{[125]}$ 
For Mo, most literature agrees that Mo first needs to be reduced (between 6+ and 4+) to be able to activate methane. ${ }^{[30-35]}$ Theoretical calculations for methane activation have been performed on fully carbidic Mo clusters, ${ }^{[126]}$ where methane adsorbs on the reduced Mo. In its carbidic form Mo has an electronic structure similar to that of noble metals and Mo carbide was also observed to behave similar to precious metals in several reactions. ${ }^{[127-129]}$ This would mean that the carbon serves merely to alter the electronic structure of Mo. In contrast to that, we recently found that the carbon that is present at the active site itself plays an important role in activating methane equivalent to oxygen in the Mars-van-Krevelen mechanism. ${ }^{[130]}$ This is indicated by the fact that the carbon from the active site was found to be incorporated into the final products. ${ }^{[94]}$ In the iron catalysed Fischer-Tropsch synthesis, iron carbide initiates the hydrocarbon chain growth ${ }^{[131,132]}$ and a similar mechanism can be envisaged for MDA. Both DFT studies and experimental work suggest that $\mathrm{CH}_{2}$ fragments can easily be formed by reaction of the carbon from the active site with gas phase hydrogen. ${ }^{[133]}$

It is conceivable that $\mathrm{W}$ and Fe behave similar to Mo and that their active forms have similar structures, since they also exhibit an induction period and were shown to form carbidic phases at reaction conditions. ${ }^{[13,48,75,134]}$

\section{C2 intermediates}

In this part, the assumption that $\mathrm{C} 2$ hydrocarbons are the main intermediates for the MDA reaction and which of ethane, ethylene or acetylene is the most likely $\mathrm{C} 2$ intermediate will be discussed. Activation of the $\mathrm{C}-\mathrm{H}$ bond in methane is slow and difficult, but as soon as the first $\mathrm{C}-\mathrm{C}$ bond is formed, further reaction becomes much easier, because $\mathrm{C} 2$ hydrocarbons are far more reactive than methane. At the same time, aromatics are thermodynamically more stable and are therefore observed as final products of the process. For these reasons, ethylene, ethane and acetylene have been proposed as the main reaction intermediates for MDA. For MTH, a reaction that shows many parallels with MDA, ethylene is often mentioned to be the main intermediate as well. ${ }^{[135]}$ Ethylene and ethane are observed as final products of the reaction, while acetylene is not, likely because of its high reactivity. Wang et al. noted that the selectivity to ethylene increases when the contact time of $\mathrm{CH}_{4}$ with $\mathrm{Mo} / \mathrm{ZSM}-5$ is shortened, demonstrating that the formation of ethylene is fast compared to the formation of aromatic products. ${ }^{[33]}$ In addition, Wang et al. did not observe an activation period when feeding $\mathrm{C}_{2} \mathrm{H}_{4}$ to $\mathrm{Mo} / \mathrm{HZSM}-5$. Both ethylene as well as acetylene were shown to immediately oligomerize with near to $100 \%$ conversion when contacted with a zeolite even at $300 \stackrel{\circ}{ }{ }^{[136]}$ while ethane reacts more slowly. ${ }^{[137]}$ With both reactants, deactivation of the catalyst due to coking is fast. ${ }^{[137]}$ Although most often ethylene, ethane and acetylene are proposed as reaction intermediates, higher intermediates are conceivable as well, especially if ethylene strongly adsorbs on the active metal and has to further react with gas-phase $\mathrm{CH}_{4}$ to desorb. This was speculated for Ag. ${ }^{[56]}$ Studying adsorption strength of ethylene at the active site however is difficult, since the structure of the active site formed at reaction conditions is unknown. Obtaining information about the dominant reaction intermediate is important, because knowledge about it facilitates designing the zeolite as a separate entity before focusing on the metal. Especially in designing superior supports factors like acidity (i.e. Si/Al, location of $\mathrm{Al}$ ) and morphology (i.e. hierarchical zeolites, nanosheets) are essential. The most mentioned and reactive intermediates, ethylene and acetylene are discussed below. 


\section{Ethylene aromatization}

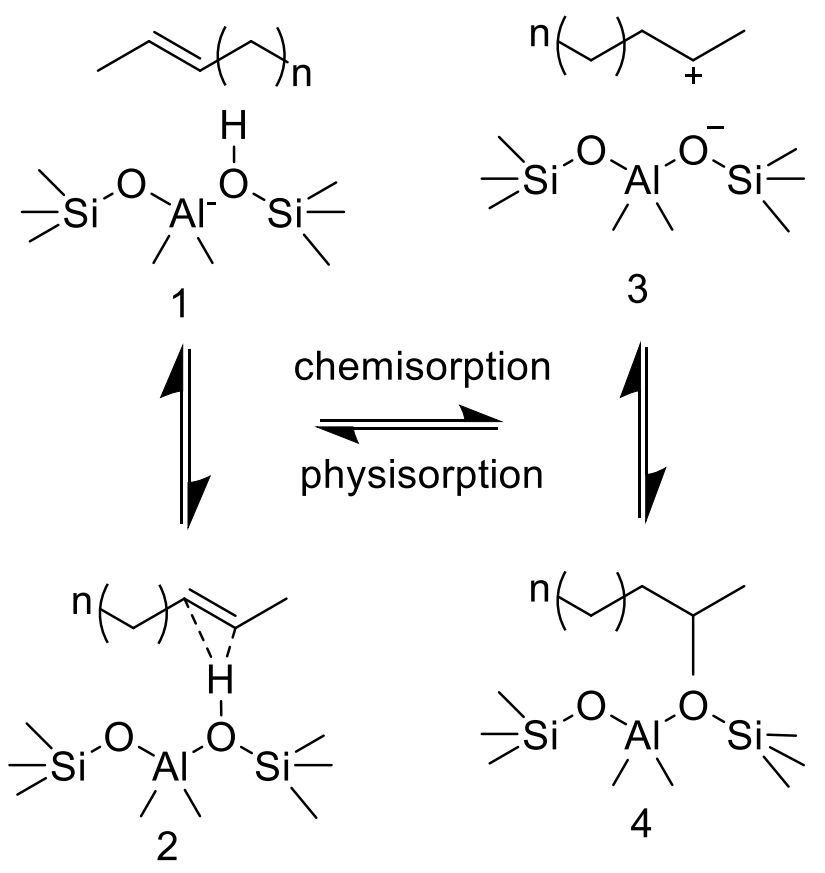

Figure 3: Four different modes of activation for an alkene - 1: Van der Waals complex, 2: $\pi$-complex, 3: carbenium ion, 4: alkoxide. ${ }^{[138]}$

Ethylene aromatization easily occurs on the BAS of a zeolite. Four different possibilities for alkene<smiles>CC=CCCCC</smiles><smiles>CCCC12CCC(CC1)C2</smiles><smiles>C[Al-](C)(O)O[Si](C)(C)C</smiles><smiles>C[Al-](C)(O[Si](C)(C)C)O[Si](C)(C)C</smiles>

1

3

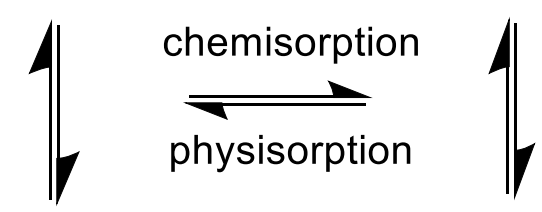

activation are mentioned in the literature (<smiles>CCCC1C=C(C)C(O[Si](C)(C)O[Si](C)(C)C)C1</smiles>

2<smiles>CCCCC(C)C(C)O[Si](C)(C)O[Si](C)(C)C</smiles>

Figure 3). ${ }^{[138]}$ But most papers assume that ethylene is activated by forming a carbocation $\left(\mathrm{C}_{2} \mathrm{H}_{5}{ }^{+}\right)$with the help of the proton from the acid site. ${ }^{[139]}$ Ethylene aromatization has been explored on HZSM-5 at $400{ }^{\circ} \mathrm{C},{ }^{[139,140]} 480{ }^{\circ} \mathrm{C},{ }^{[141]} 500{ }^{\circ} \mathrm{C}^{[137,142]}$ and $540{ }^{\circ} \mathrm{C}^{[143]}$ using very diluted streams of ethylene to slow down coking. Qiu et al. explored the conversion of ethylene between 300 and $650^{\circ} \mathrm{C}$ and found that the selectivity to aromatics increases with temperature. ${ }^{[136]}$ However, only when introducing gallium $(\mathrm{Ga})$ to the zeolite, immediate 
deactivation due to coking could be avoided at higher temperatures. When introducing metals into the zeolite, the proton at the BAS is replaced by the metal, thereby decreasing overall acidity, which leads to a lower activity, slower coking rates and with that a longer lifetime of the catalyst. But apart from slowing down coking, introducing a metal also increases the selectivity to aromatics, suggesting that the metal also plays a role in the aromatization steps. ${ }^{[139,140,144]}$ The metal acts as a Lewis acid site (LAS) and its role is believed to be the abstraction of hydrogen. For $\mathrm{Ga}^{3+}$ it was speculated that non-aromatic $\mathrm{C} 4$ and $\mathrm{C} 6$ are first formed on the BAS and then dehydrogenated on $\mathrm{Ga}^{3+}$ to form aromatics. ${ }^{[136]}$ Similarly, a DFT study revealed a lower activation energy for ethylene towards aromatics on BAS than on silver $\left(\mathrm{Ag}^{+}\right)$, also suggesting that ethylene is first activated via the acidic proton and then dehydrocyclized on $\mathrm{Ag}^{+} .{ }^{[139]}$ Interestingly, for methanol to aromatics (MTA), a linear relationship between $\mathrm{Zn}$ sites and aromatics selectivity was found for low loadings of $\mathrm{Zn}$ between 0.4 and $1.5 \mathrm{wt} . \%$ matching what was found for ethylene conversion. ${ }^{[141,145]}$ In contrast to this, when $\mathrm{Zn}$ is present as $\mathrm{ZnO}$ clusters at the mouth of the zeolite pores, it was suggested that it helps to expel hydrogen from the catalyst. ${ }^{[146]}$ It was however also found that bigger $\mathrm{ZnO}$ clusters hydrogenate ethylene to ethane and therefore lower the aromatization activity. ${ }^{[141]}$ For all metals an overall increase in ethylene conversion and aromatics selectivity was observed after introduction of the metal to HZSM-5, while even at $650 \stackrel{\circ}{\circ}$, the aromatics yield remained as low as $17 \%$ on bare HZSM-5. ${ }^{[136]}$

\section{Acetylene aromatization}

Because of its high reactivity, the gas phase aromatization of acetylene over heterogeneous catalysts is hard to control and fast coking occurs even below $400^{\circ} \mathrm{C} .{ }^{[147,148]}$ The most recent

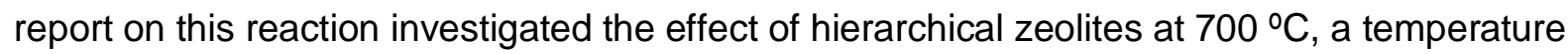
typically also applied for MDA. ${ }^{[149]} \mathrm{A}$ very diluted stream of acetylene was co-fed together with hydrogen and a BTX selectivity of up to $80 \%$ was reached with benzene being the main product, and resembling the product distribution for MDA.

\section{What is the most likely intermediate?}

Mériaudeau et al. tried to determine what the dominant intermediate for MDA is, ethylene or rather acetylene. ${ }^{[144,150]}$ Acetylene, being the more reactive molecule, exhibited higher benzene formation rates than ethylene. They found that similar to $\mathrm{Zn}, \mathrm{Ga}$ and $\mathrm{Ag}$, the presence of Mo on HZSM-5 leads to four times higher benzene formation from ethylene than on the bare HZSM-5. Surprisingly, even $\mathrm{Mo} / \mathrm{SiO}_{2}$, which possesses no BAS was much more active than $\mathrm{H}-\mathrm{ZSM}-5$ for benzene formation with a $\mathrm{C}_{2} \mathrm{H}_{4} / \mathrm{H}_{2} / \mathrm{N}_{2}$ feed. Generally, when feeding ethylene, the selectivity to toluene (about the same as to benzene) seems to be higher than for MDA ${ }^{[137]}$ while the selectivity to toluene and benzene mimics those of MDA more closely for acetylene/ $\mathrm{H}_{2}$ mixtures. ${ }^{[149]}$ Acetylene is not observed as a product of the MDA reaction, likely due to its high reactivity. It was also found that acetylene easily hydrogenates to ethylene in the presence of hydrogen, which can explain that ethylene is observed as a consecutive product. ${ }^{[148]}$ Observing the intermediate at reaction conditions spectroscopically is very difficult and isotopic labeling studies only provide indirect information. ${ }^{[151]}$ DFT studies of possible $\mathrm{CH}_{4}$ dimerization pathways were attempted before, but are difficult to validate because of the lack of knowledge about the structure of the active site. ${ }^{[152,153]}$ Further insight on which $\mathrm{C} 2$ hydrocarbon is the most likely intermediate can be gained from thermodynamic considerations. For this review, we investigated the thermodynamics of all three suggested intermediates, acetylene, ethylene and ethane using Aspen+ (Figure 4). 
a) Acetylene

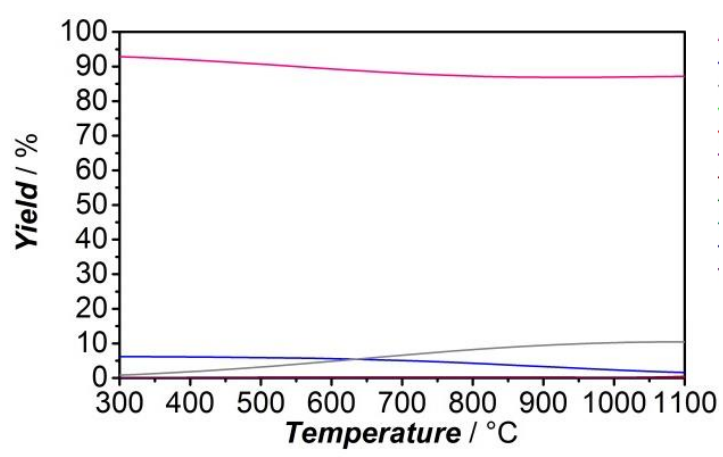

c) Ethane

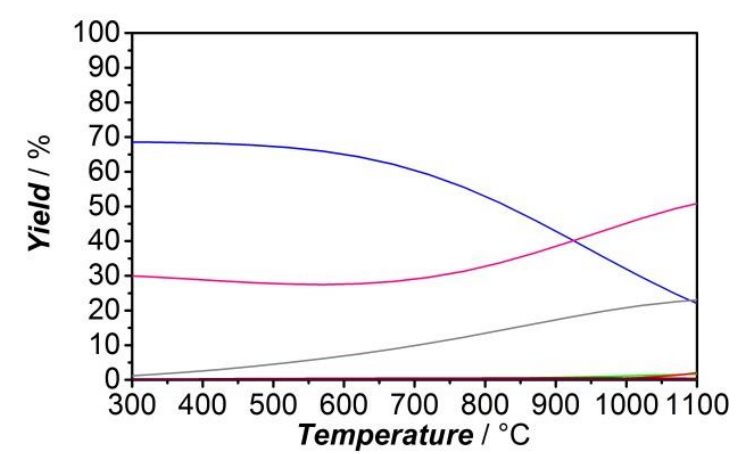

b) Ethylene

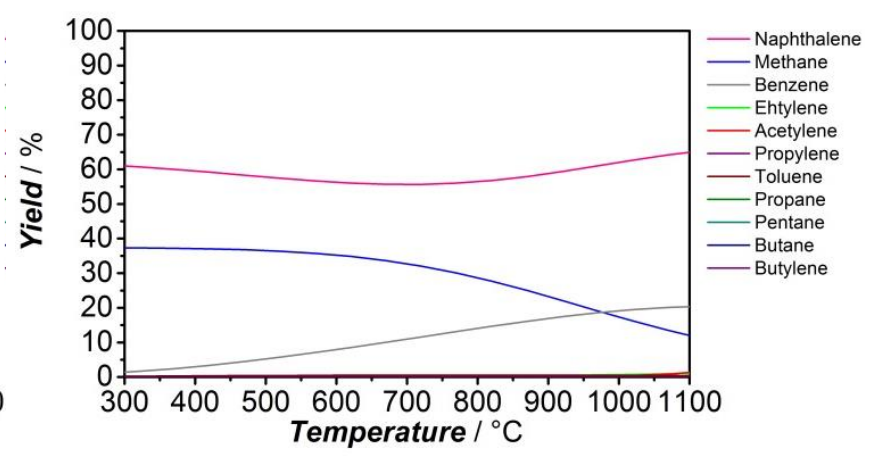

d) Methane

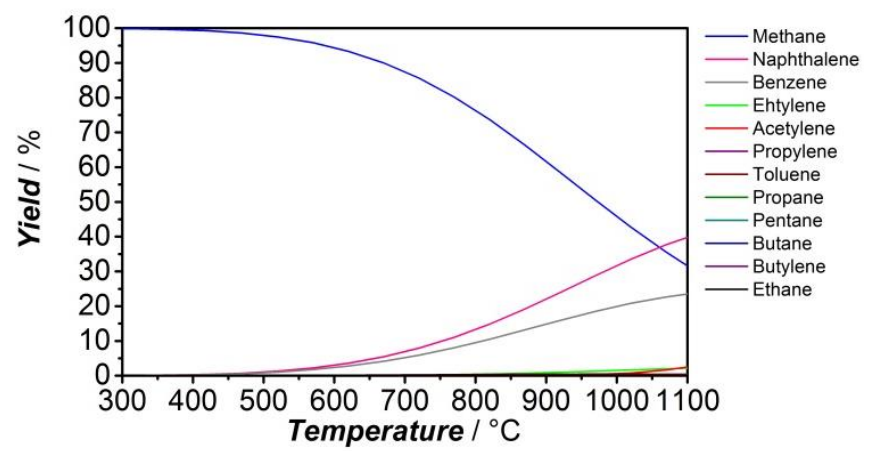

Figure 4: Equilibrium yields of methane, naphthalene, benzene, ethylene, acetylene, propylene, toluene, propane, pentane, butane, butylene and ethane with a) acetylene, b) ethylene, c) ethane and d) methane defined as reactant. Equilibrium concentrations were calculated using the Aspen+ software.

Excluding solid carbon, the following products were allowed to form: methane, naphthalene, benzene, toluene, propylene, propane, butylene, butane, pentane, the other $\mathrm{C} 2$ hydrocarbons not defined as the reactant and hydrogen. The results for the three $\mathrm{C} 2$ hydrocarbons were then compared to $\mathrm{CH}_{4}$ conversion to the same products. All three reactants form predominantly methane and naphthalene followed by benzene, all other products are formed in negligible amounts. This means that $\mathrm{C} 2-\mathrm{C} 5$ hydrocarbons, if observed during the catalytic tests are mostly kinetic products. The equilibria when acetylene, ethylene or ethane is defined as reactant only differ in the amount of methane and naphthalene formed, while benzene yields are fairly similar. 


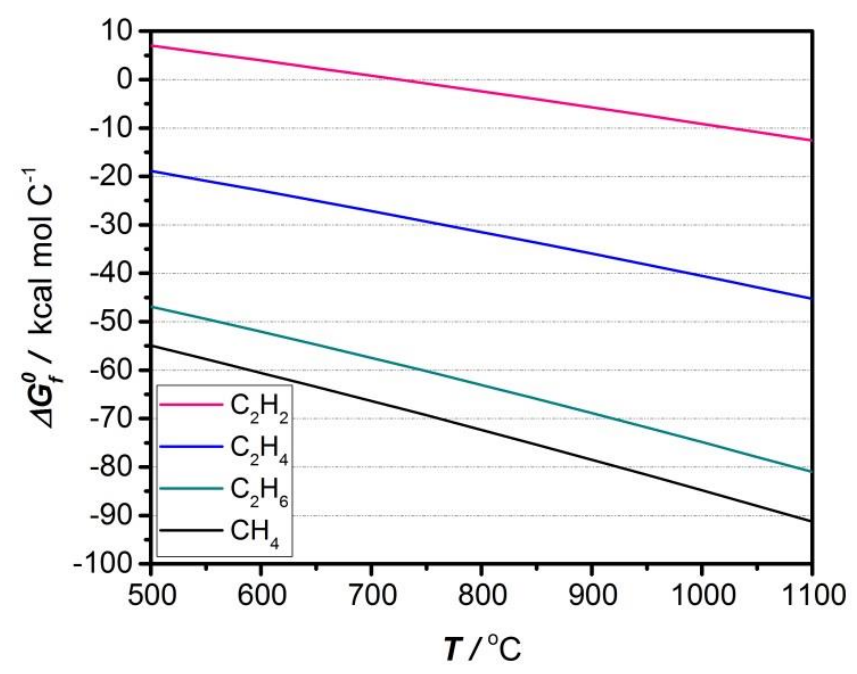

Figure 5: Standard Gibb's free energy of formation of methane, acetylene, ethylene and ethane as a function of temperature, normalized by carbon number as obtained from the HSC 6 database.

Figure 5 shows the standard Gibb's free energy of formation $\left(\Delta G_{f}^{0}\right)$ of methane, acetylene, ethylene and ethane as a function of temperature. The standard Gibb's free energy of reaction $\left(\Delta G_{r}^{0}\right)$ can be computed approximately from $\Delta G_{f}^{0}$ using $\Delta G_{r}^{0}=\sum_{B} v_{\mathrm{B}} \Delta G_{f}^{0}(B) \cdot{ }^{[154]}$ The higher the hydrogen to carbon ratio of the $\mathrm{C} 2$ hydrocarbon, the more stable methane is compared to it and the reaction towards methane becomes more favorable (more negative $\left.\Delta G_{r}^{0}\right)$. At the same time the propensity to form naphthalene decreases. As a consequence, the naphthalene to benzene ratio decreases with increasing $\mathrm{H} / \mathrm{C}$ and is lowest, when pure methane is the reactant. The thermodynamic analysis shows that with all suggested intermediates naphthalene is the most dominant thermodynamic product followed by benzene. This provides an alternative explanation for why the aromatics selectivity increases upon introducing a metal to the zeolite. The metal acts to speed up the reaction and drive it more towards the thermodynamic product distribution.

\section{Topology, Brønsted acidity and the aromatization reactions}

Shape selectivity and acidity are the two inherent properties of zeolites and the two main reasons of their vast utilization in catalysis. ${ }^{[155]}$ Brønsted acidity in zeolites is represented by the proton counterbalancing the negative charge of the zeolite framework, created by substituting tetravalent Si by trivalent Al (or some other elements). ${ }^{[156]}$ Not only the amount of acid sites, but also their location and distribution are important parameters determining performance in zeolite catalysis. ${ }^{[157]}$ In this paragraph we will discuss how they affect aromatization reactions.

There are many works dedicated to the effect of Brønsted acid site concentration on aromatization performance. ${ }^{[11,158]}$ Generally, Brønsted acid sites carry several functions. The first function is related to the dispersion of the active metal inside the zeolite micropores (vide supra). Only, if the metal is finely dispersed inside the pores of the zeolite can it activate methane. It is generally recognized that the role of Mo species is to activate methane which results in $\mathrm{C} 2$ formation, while the subsequent conversion of $\mathrm{C} 2$ to benzene is performed on the acid site. ${ }^{[10]}$ Thus, the second function of zeolite Brønsted acidity is to perform 
aromatization of intermediates formed on Mo sites. The decisive role of Brønsted acidity is further confirmed by the fact that Mo/Na-ZSM-5 is inactive in MDA. ${ }^{[5]}$ To avoid excessive coking while retaining high benzene formation rate, it is generally recommended to use zeolites with moderate acidity. High Al content promotes condensation reactions of the products leading to the formation of the so-called hard coke (highly dehydrogenated polyaromatics). ${ }^{[7]}$ On the other hand, it was shown that low Al content results in low benzene and toluene selectivity, yielding mainly ethylene in ethane aromatization. ${ }^{[159]}$ Kosinov et al. recently hypothesized that MDA reaction mechanism might have features similar to methanol-to-hydrocarbons (MTH) mechanism claiming that primary $\mathrm{C}_{2} \mathrm{H}_{\mathrm{x}}$ fragments react with linear polyaromatic species trapped in zeolitic microenvironment. ${ }^{[160]}$ From such a perspective, the structure-performance relationship deduced from the MTH studies can be applied to MDA and paraffins/olefins aromatization reactions. ${ }^{[22,161,162]}$ It can be expressed in the following manner: "the higher the density of acid sites, the closer these sites are to each other, the larger the number of successive chemical steps undergone by reactant molecules along the diffusion path within the zeolite crystallites and the more favourable the condensation reactions, hence the faster the coking rate."[163] To tackle high coking rates, a variety of methods are used to tune acidity and to passivate acid sites at the external surface. For example, Lu et al. performed de-alumination of ZSM- 5 by steaming which resulted in a significantly lower selectivity to coke $(18.9 \%$ vs $37.9 \%)$, naturally leading to higher benzene yield. ${ }^{[164]}$ Acid site concentration and acid strength is also altered by the high temperature applied for MDA similar to the heat-treatment applied to prepare silica for grafting. ${ }^{[165-167]}$

In summary, while anchoring an active metal requires low Si/Al ratios, aromatization of active intermediates without high coking rates calls for zeolites with moderate acidity. According to $\mathrm{Ma}$ et al. an ideal MDA catalyst should have an appropriate balance between the free Brønsted acid sites and acid sites with anchored Mo. ${ }^{[168]}$ By utilizing Mo/MCM-22 with different Mo loading, they showed that the best catalyst possessed three Al per unit cell, where one framework $\mathrm{Al}$ was associated with aromatization reaction, while other two were used to anchor Mo.

To the best of our knowledge, for methane dehydroaromatization as well as aromatization of olefins/paraffins ZSM-5 and MCM-22-based catalysts show by far the highest performance compared to other zeolite topologies. ${ }^{[169]}$ The ZSM- 5 choice is dictated by a rather peculiar architecture of MFI topology, consisting of interconnecting straight $(5.3 \times 5.6 \AA)$ and zig-zag $(5.1 \times 5.5 \AA)$ channels able to accommodate aromatics up to methylated naphthalene or longer aromatic chains like anthracene. The fact that these two structures outperform other structures with similar pore sizes and acid strength for a lot of reactions, like FCC, MTH and alkane/alkene conversion was also assigned to confinement effects. They influence in which configuration reactants interact with the active site and are believed to play a significant role in determining the activity of those two zeolite topologies. ${ }^{[170-172]}$ Kosinov et al. showed that in the absence of zeolite, molybdenum supported on different oxides such as $\mathrm{SiO}_{2}$ and $\mathrm{Al}_{2} \mathrm{O}_{3}$, can activate methane with minor formation of aromatics and aliphatics, but coke is the main product. ${ }^{[40,124]}$ Authors showed that the confinement of metal in zeolite pores shifts selectivity to benzene and its homologues increasing the overall yield of value-added products. ${ }^{[173]}$ However, not all zeolite topologies are equally selective to aromatics. In small-pore zeolites with large cavities (8MR), any aromatic molecule is locked up in such a cavity making the catalyst selective almost exclusively to ethylene and ethane. ${ }^{[174,175]}$ Although such a catalyst does not have any perspective for practical application, it highlights the important role of 
ethylene as an intermediate. Another extreme is utilization of large pore zeolites (12MR), such as X, Y, MOR, BEA and many others. ${ }^{[40,61,175]}$ Their architectures with large pores and channels do not restrict benzene to react further and form polycondensed structures, which are coke pre-cursors. As a consequence, similar to oxide supports, this class of zeolites is selective to coke rather than benzene derivatives. ${ }^{[174]}$ ZSM- 5 belonging to $10 \mathrm{MR}$ family seems to be the optimal choice as its confinement allows formation of naphthalene, benzene, toluene and xylenes, while restricting further growth to polycondensed structures. Similarly to ZSM-5, many other 10MR zeolites exhibit high selectivity to aromatics. ${ }^{[158,176-179]}$ Kan et al.extensively studied the influence of zeolite topology on activity and selectivity in MDA reaction. ${ }^{[177-179]}$ The general conclusion was that all studied 10MR zeolites behaved rather similar to ZSM-5 as a result of comparable channel dimensions. Zeolites having additional 12-ring cavity (TNU-9) were more selective to benzene than ZSM-5 (81.2 vs $67.4 \%$ ), while zeolites with additional 9MR ring windows (ITQ-13) deactivated noticeably faster. Martinez et al. ${ }^{[180]}$ compared the catalytic activity of Mo/MCM-22 and Mo/ITQ-2 (delaminated layered pre-cursor of MCM-22) in MDA reaction. Both showed rather high selectivity to benzene, ITQ-2 being more selective to naphthalene. Further de-alumination of external surface of ITQ-2 resulted in an increase to benzene selectivity from 62 to $75 \%$ at the expense of naphthalene, suggesting that it is formed on the outer surface of the zeolite and confirming the profound effect of shape-selectivity. It is worth mentioning that Mo/MCM-22 (MWW) shows catalytic performance comparable to Mo/ZSM-5 in MDA reaction. ${ }^{[10]}$ It possesses a set of $12 \mathrm{MR}$ cages connected through $10 \mathrm{MR}$ windows and a set of $10 \mathrm{MR}$ channels. It is not clear however which of the two pore systems is responsible for the catalytic performance. ${ }^{[181]}$

\section{A bifunctional catalyst and the two-step mechanism}

The Mo in combination with the acidic zeolite support was proposed to make up the bifunctional nature of this catalyst. In a two-step process, the two sites are believed to fulfill two distinct functions. Mo achieves $\mathrm{C}-\mathrm{H}$ activation of methane and leads to the formation of C2 intermediates, which then react over the BAS of the zeolite, where they aromatize. This mechanism was proposed early on ${ }^{[5]}$ and was mostly accepted since then. ${ }^{[36-39]}$ This proposed mechanism is supported by the fact that $\mathrm{CH}_{4}$ activation solely over BAS is negligible, ${ }^{[0-42]}$ and therefore a metal site is necessary to activate $\mathrm{CH}_{4}$. In contrast to the twostep mechanism, it was proposed that Mo does not achieve $\mathrm{C}-\mathrm{H}$ bond activation on its own but in concert with the BAS, which helps in abstracting the proton from $\mathrm{CH}_{4}{ }^{[36,54,55]}$ This is also supported by the fact that there are only two active non-zeolite based catalysts reported for this reaction. ${ }^{[125,182]} \mathrm{A}$ concerted action or at least the requirement of close proximity of the Mo and BAS is also suggested by the fact that physically mixing Mo carbides with zeolite only leads to very low activity. ${ }^{[183]}$ Furthermore, in ethylene aromatization both ethylene conversion as well as aromatic selectivity was much enhanced when a metal was added to HZSM-5. ${ }^{[139,140,144]}$ This suggests that Mo also plays a crucial role in aromatics production. In conclusion, the separation of these functionalities is not possible. ${ }^{[184]}$ Although some studies address the optimal loading of Mo, given a zeolite with certain acidity and vice versa, ${ }^{36,37,77-}$ 79, 168] the optimal proximity of BAS to Mo site and the optimal concentration of both sites per zeolite cage is only discussed for MCM-22. ${ }^{[168]}$ A careful study is necessary, both varying $\mathrm{Mo} / \mathrm{Al}$ ratios as well as $\mathrm{Si} / \mathrm{Al}$ ratios over a wide range while carefully characterizing how many well-dispersed Mo sites are created inside the pores of the zeolite. This could be achieved by probing how many BAS are replaced by Mo, probing acidity through $\mathrm{H} / \mathrm{D}$ exchange, ${ }^{[43,75,81]}$ 
${ }^{1} \mathrm{H}$ NMR, ${ }^{[122]} \mathrm{Al} \mathrm{NMR},{ }^{[109,110]} \mathrm{NH}_{3}$-TPD ${ }^{[52,77,112,113]}$ or probing adsorbed molecules by FTIR. ${ }^{[40,}$ 114]

An alternative reaction mechanism proposed proceeds via methyl radicals. ${ }^{[36]}$ While their role for MDA over zeolite catalysts is mostly speculative, they have been shown to play a role above $1000 \stackrel{\circ}{ } \mathrm{C}$ when a $\mathrm{Fe} @ \mathrm{SiO}_{2}$ catalyst with a very low surface area was used. Methyl radicals were also observed to play an important role in the oxidative coupling of methane. ${ }^{[151,}$ 182, 185] The presence of radicals can be investigated using operando electron spin resonance (ESR) or online vacuum ultraviolet soft photoionization molecular-beam mass spectrometry (VUVSPI-MBMS). ${ }^{[151,182,186]}$

\section{Outlook}

It is clear that significant research effort is necessary to further improve the performance of the MDA catalyst. To bring it to a stage where the development of a commercial process can be considered, the selectivity to coke has to be decreased, the catalyst needs to be resistant to degradation during regeneration and a catalyst more selective to benzene rather than naphthalene is required: on one hand, commercial interest in naphthalene is rather low, on the other hand, formation of such heavy product would bring serious operational issues in commercial plants. Spotting the metal sites that achieve methane activation among the plethora of metal sites present on the catalyst, however difficult, is crucial. A structure-activity relationship has however not been developed for the MDA system. This would have tremendous impact on catalyst design. Effort should be directed towards designing a catalyst containing only well-dispersed metal sites preventing metal nanoparticles and Mo clustering. Pretreatments could play an important role in that regard as they can stabilize the active site and avoid coke formation in the initial periods of the reaction. In addition, elimination of the induction period through a pretreatment could facilitate process operation especially during the startup of the reaction. ${ }^{[187]}$ Singling out the main reaction intermediate has not been achieved yet, but can aid in designing better supports by feeding reaction intermediates directly to the support without the metal. With this, the optimization of the catalyst system becomes easier, because several optimization parameters can be separated by first optimizing the support and then later the dispersion of the metal on the already optimized support. Metal-support interaction and inherent reactivity of the support can then be studied as two separate phenomena and optimized separately, making it a more manageable task.

\section{Acknowledgements}

Financial support from the Sabic-NWO CATC1CHEM CHIPP project is gratefully acknowledged. We especially thank Dr. Christoph Dittrich (SABIC), Dr. Frank Mostert (SABIC) and Dr. T. Alexander Nijhuis (SABIC) for helpful discussion.

\section{References}

[1] M. Bender in Global Aromatics Supply - Today and Tomorrow, Vol. 2, DGMK Conference, City, 2013.

[2] N. E. T. Laboratory in An introduction to the science and energy potential of a unique resource, US Department of Energy, City, 2011.

[3] C. Elvidge, M. Zhizhin, K. Baugh, F.-C. Hsu, T. Ghosh Energies. 2016, 9, 14.

[4] P. Tang, Q. Zhu, Z. Wu, D. Ma Energy Environ. Sci.. 2014, 7, 2580-2591. 
[5] L. Wang, L. Tao, M. Xie, G. Xu, J. Huang, Y. Xu Catal. Lett. 1993, 21, 35-41.

[6] O. Bragin, T. Vasina, Y. I. Isakov, B. Nefedov, A. Preobrazhenskii, N. Palishkina, K. M. Minachev Russ. Chem. Bull. 1982, 31, 847-847.

[7] B. S. Liu, L. Jiang, H. Sun, C. T. Au Appl. Surf. Sci.. 2007, 253, 5092-5100.

[8] K. Honda, X. Chen, Z.-G. Zhang Catal. Commun. 2004, 5, 557-561.

[9] Y. Song, Y. Xu, Y. Suzuki, H. Nakagome, Z.-G. Zhang Appl. Catal., A. 2014, 482, 387-396.

[10] J. J. Spivey, G. Hutchings Chem. Soc. Rev. 2014, 43, 792-803.

[11] S. Ma, X. Guo, L. Zhao, S. Scott, X. Bao Journal of Energy Chemistry. 2013, 22, 1-20.

[12] B. M. Weckhuysen, D. Wang, M. P. Rosynek, J. H. Lunsford Journal of Catalysis. 1998, 175, 347351.

[13] B. M. Weckhuysen, D. Wang, M. P. Rosynek, J. H. Lunsford J. Catal. 1998, 175, 338-346.

[14] Y. Shu, M. Ichikawa Catal. Today. 2001, 71, 55-67.

[15] N. Y. Chen, T. Y. Yan Ind. Eng. Chem. Process Des. Dev. 1986, 25, 151-155.

[16] T. F. Degnan, G. K. Chitnis, P. H. Schipper Microporous Mesoporous Mater. 2000, 35-36, 245-252.

[17] J. F. Haw, D. M. Marcus Top. Catal. 2005, 34, 41-48.

[18] J. F. Haw, W. Song, D. M. Marcus, J. B. Nicholas Acc. Chem. Res. 2003, 36, 317-326.

[19] U. Olsbye, M. Bjørgen, S. Svelle, K.-P. Lillerud, S. Kolboe Catal. Today. 2005, 106, 108-111.

[20] P. W. Goguen, T. Xu, D. H. Barich, T. W. Skloss, W. Song, Z. Wang, J. B. Nicholas, J. F. Haw J. Am. Chem. Soc. 1998, 120, 2650-2651.

[21] K. Hemelsoet, J. Van der Mynsbrugge, K. De Wispelaere, M. Waroquier, V. Van Speybroeck ChemPhysChem. 2013, 14, 1526-1545.

[22] U. Olsbye, S. Svelle, M. Bjørgen, P. Beato, T. V. W. Janssens, F. Joensen, S. Bordiga, K. P. Lillerud Angew. Chem. Int. Ed. 2012, 51, 5810-5831.

[23] I. Yarulina, S. Bailleul, A. Pustovarenko, J. R. Martinez, K. D. Wispelaere, J. Hajek, B. M. Weckhuysen, K. Houben, M. Baldus, V. Van Speybroeck, F. Kapteijn, J. Gascon ChemCatChem. 2016, 8, 3057-3063.

[24] I. Yarulina, J. Goetze, C. Gucuyener, L. van Thiel, A. Dikhtiarenko, J. Ruiz-Martinez, B. M. Weckhuysen, J. Gascon, F. Kapteijn Catal. Sci. Technol. 2016, 6, 2663-2678.

[25] J. Goetze, F. Meirer, I. Yarulina, J. Gascon, F. Kapteijn, J. Ruiz-Martínez, B. M. Weckhuysen ACS Catal. 2017, 7, 4033-4046.

[26] I. M. Dahl, S. Kolboe Catal. Lett. 1993, 20, 329-336.

[27] N. Kosinov, A. S. G. Wijpkema, E. Uslamin, R. Rohling, F. J. A. G. Coumans, B. Mezari, A. Parastaev, A. S. Poryvaev, M. V. Fedin, E. A. Pidko, E. J. M. Hensen Angew. Chem. Int. Ed. 2018, 57, 1016-1020. [28] K. S. Wong, J. W. Thybaut, E. Tangstad, M. W. Stöcker, G. B. Marin Microporous Mesoporous Mater. 2012, 164, 302-312.

[29] C. Karakaya, H. Zhu, R. J. Kee Chem. Eng. Sci. 2015, 123, 474-486.

[30] H. Jiang, L. Wang, W. Cui, Y. Xu Catal. Lett. 1999, 57, 95-102.

[31] I. Lezcano-González, R. Oord, M. Rovezzi, P. Glatzel, S. W. Botchway, B. M. Weckhuysen, A. M. Beale Angew. Chem. Int. Ed. 2016, 55, 5215-5219.

[32] F. Solymosi, A. Szöke, J. Cserényi Catal. Lett. 1996, 39, 157-161.

[33] D. Wang, J. Lunsford, M. Rosynek Top. Catal. 1996, 3, 289-297.

[34] S. Liu, L. Wang, R. Ohnishi, M. Lchikawa Kinet. Catal. 2000, 41, 132-144.

[35] W. Ding, S. Li, G. D Meitzner, E. Iglesia J. Phys. Chem. B. 2001, 105, 506-513.

[36] L. Y. Chen, L. W. Lin, Z. S. Xu, X. S. Li, T. Zhang J. Catal. 1995, 157, 190-200.

[37] Y. Xu, S. Liu, X. Guo, L. Wang, M. Xie Catal. Lett. 1994, 30, 135-149.

[38] Y. Xu, W. Liu, S.-T. Wong, L. Wang, X. Guo Catal. Lett. 1996, 40, 207-214.

[39] F. Solymosi, J. Cserényi, A. Szöke, T. Bánsági, A. Oszkó J. Catal. 1997, 165, 150-161.

[40] S. Liu, L. Wang, R. Ohnishi, M. Ichikawa J. Catal. 1999, 181, 175-188.

[41] V. T. T. Ha, L. V. Tiep, P. Meriaudeau, C. Naccache J. Mol. Catal. A: Chem. 2002, 181, 283-290.

[42] R. E. Jentoft, B. C. Gates Catal. Lett. 2001, 72, 129-133.

[43] Y.-H. Kim, R. W. Borry, E. Iglesia Microporous Mesoporous Mater. 2000, 35, 495-509.

[44] B. M. Weckhuysen, M. P. Rosynek, J. H. Lunsford Catal. Lett. 1998, 52, 31-36. 
[45] F. Solymosi, A. Erdöhelyi, A. Szöke Catal. Lett. 1995, 32, 43-53.

[46] Y. Xu, L. Lin Appl. Catal., A. 1999, 188, 53-67.

[47] H. Liu, W. Shen, X. Bao, Y. Xu J. Mol. Catal. A: Chem. 2006, 244, 229-236.

[48] P. Tan J. Catal. 2016, 338, 21-29.

[49] L. Wang, R. Ohnishi, M. Ichikawa J. Catal. 2000, 190, 276-283.

[50] P. L. Tan, C. T. Au, S. Y. Lai Catal. Lett. 2006, 112, 239-245.

[51] T. Baba, H. Sawada Phys. Chem. Chem. Phys. 2002, 4, 3919-3923.

[52] B. S. Liu, Y. Zhang, J. F. Liu, M. Tian, F. M. Zhang, C. T. Au, A. S. C. Cheung J. Phys. Chem. C. 2011, 115, 16954-16962.

[53] V. Abdelsayed, M. W. Smith, D. Shekhawat Appl. Catal., A. 2015, 505, 365-374.

[54] V. B. Kazansky, A. I. Serykh, E. A. Pidko J. Catal. 2004, 225, 369-373.

[55] G. Qi, Q. Wang, J. Xu, J. Trébosc, O. Lafon, C. Wang, J. P. Amoureux, F. Deng Angew. Chem. Int. Ed. 2016.

[56] A. A. Gabrienko, S. S. Arzumanov, I. B. Moroz, A. V. Toktarev, W. Wang, A. G. Stepanov J. Phys. Chem. C. 2013, 117, 7690-7702.

[57] T. Baba, Y. Abe Appl. Catal., A. 2003, 250, 265-270.

[58] A. A. Gabrienko, S. S. Arzumanov, I. B. Moroz, I. P. Prosvirin, A. V. Toktarev, W. Wang, A. G.

Stepanov J. Phys. Chem. C. 2014, 118, 8034-8043.

[59] Y. Xu, L. Lin Appl. Catal., A. 1999, 188, 53-67.

[60] Y. Xu, X. Bao, L. Lin J. Catal. 2003, 216, 386-395.

[61] Z. R. Ismagilov, E. V. Matus, L. T. Tsikoza Energy Environ. Sci.. 2008, 1, 526-541.

[62] S. Majhi, P. Mohanty, H. Wang, K. K. Pant Journal of Energy Chemistry. 2013, 22, 543-554.

[63] R. Horn, R. Schlögl Catal. Lett. 2015, 145, 23-39.

[64] A. I. Olivos Suarez, Á. Szécsényi, E. J. M. Hensen, J. Ruiz-Martínez, E. A. Pidko, J. Gascon ACS Catal. 2016.

[65] I. Vollmer, G. Li, I. Yarulina, N. Kosinov, E. J. Hensen, K. Houben, D. Mance, M. Baldus, J. Gascon, F. Kapteijn Catal. Sci. Technol. 2018, 8, 916-922.

[66] E. V. Matus, I. Z. Ismagilov, O. B. Sukhova, V. I. Zaikovskii, L. T. Tsikoza, Z. R. Ismagilov, J. A. Moulijn Ind. Eng. Chem. Res. 2007, 46, 4063-4074.

[67] J. Gao, Y. Zheng, J.-M. Jehng, Y. Tang, I. E. Wachs, S. G. Podkolzin Science. 2015, 348, 686-690.

[68] C. Sun, S. Yao, W. Shen, L. Lin Catal. Lett. 2008, 122, 84-90.

[69] M. Bäumer, H.-J. Freund Prog. Surf. Sci. 1999, 61, 127-198.

[70] H. J. Freund, M. Bäumer, H. Kuhlenbeck in Catalysis and surface science: What do we learn from studies of oxide-supported cluster model systems?, Vol. 45, Academic Press, 2000, pp.333-384.

[71] J. C. Fierro-Gonzalez, S. Kuba, Y. Hao, B. C. Gates J. Phys. Chem. B. 2006, 110, 13326-13351.

[72] C. Copéret, M. Chabanas, R. Petroff Saint-Arroman, J.-M. Basset Angew. Chem. Int. Ed. 2003, 42, 156-181.

[73] C. Copéret, A. Comas-Vives, M. P. Conley, D. P. Estes, A. Fedorov, V. Mougel, H. Nagae, F. NúñezZarur, P. A. Zhizhko Chem. Rev. 2016, 116, 323-421.

[74] C. Coperet Chem. Rev. 2010, 110, 656-680.

[75] W. Ding, G. D. Meitzner, D. O. Marler, E. Iglesia J. Phys. Chem. B. 2001, 105, 3928-3936.

[76] S. Liang, C. Hao, Y. Shi ChemCatChem. 2015, 7, 2559-2567.

[77] J.-P. Tessonnier, B. Louis, S. Rigolet, M. J. Ledoux, C. Pham-Huu Appl. Catal., A. 2008, 336, 79-88.

[78] J. Gao, Y. Zheng, J.-M. Jehng, Y. Tang, I. E. Wachs, S. G. Podkolzin Science. 2015.

[79] J. Shu, A. Adnot, B. P. A. Grandjean Ind. Eng. Chem. Res. 1999, 38, 3860-3867.

[80] T. H. Lim, K. Nam, I. K. Song, K.-Y. Lee, D. H. Kim Appl. Catal., A. 2018, 552, 11-20.

[81] J.-P. Tessonnier, B. Louis, S. Walspurger, J. Sommer, M.-J. Ledoux, C. Pham-Huu J. Phys. Chem. B. 2006, 110, 10390-10395.

[82] C. Hammond, M. M. Forde, M. H. Ab Rahim, A. Thetford, Q. He, R. L. Jenkins, N. Dimitratos, J. A. Lopez-Sanchez, N. F. Dummer, D. M. Murphy, A. F. Carley, S. H. Taylor, D. J. Willock, E. E. Stangland, J. Kang, H. Hagen, C. J. Kiely, G. J. Hutchings Angew. Chem. Int. Ed. 2012, 51, 5129-5133.

[83] V. L. Sushkevich, D. Palagin, M. Ranocchiari, J. A. van Bokhoven Science. 2017, 356, 523-527. 
[84] G. Centi, F. Vazzana Catal. Today. 1999, 53, 683-693.

[85] N. Kosinov, C. Liu, E. J. M. Hensen, E. A. Pidko Chem. Mater. 2018.

[86] J. Raskó, J. Kiss Appl. Catal., A. 2003, 253, 427-436.

[87] J. B. Peri J. Phys. Chem. 1982, 86, 1615-1622.

[88] R. J. Lobo-Lapidus, B. C. Gates Langmuir. 2010, 26, 16368-16374.

[89] J. F. Goellner, B. C. Gates, G. N. Vayssilov, N. Rösch J. Am. Chem. Soc. 2000, 122, 8056-8066.

[90] T.-c. Xiao, A. P. E. York, V. C. Williams, H. Al-Megren, A. Hanif, X.-y. Zhou, M. L. H. Green Chem. Mater. 2000, 12, 3896-3905.

[91] T. M. Duncan, P. Winslow, A. T. Bell J. Catal. 1985, 93, 1-22.

[92] G. H. Yokomizo, A. T. Bell J. Catal. 1989, 119, 467-482.

[93] T. Xiao, A. P. E. York, K. S. Coleman, J. B. Claridge, J. Sloan, J. Charnock, M. L. H. Green J. Mater. Chem. 2001, 11, 3094-3098.

[94] I. Vollmer, B. van der Linden, S. Ould-Chikh, A. Aguilar-Tapia, I. Yarulina, E. Abou-Hamad, Y. G. Sneider, A. I. Olivos Suarez, J.-L. Hazemann, F. Kapteijn, J. Gascon Chem. Sci. 2018, 9, 4801-4807.

[95] D. Ma, W. Zhang, Y. Shu, X. Liu, Y. Xu, X. Bao Catal. Lett. 2000, 66, 155-160.

[96] D. Ma, Y. Shu, X. Bao, Y. Xu J. Catal. 2000, 189, 314-325.

[97] H. Zheng, D. Ma, X. Bao, J. Z. Hu, J. H. Kwak, Y. Wang, C. H. F. Peden J. Am. Chem. Soc. 2008, 130, 3722-3723.

[98] R. Kumar Rana, B. Viswanathan Catal. Lett. 1998, 52, 25-29.

[99] R. O. Savinelli, S. L. Scott Phys. Chem. Chem. Phys. 2010, 12, 5660-5667.

[100] J. P. Thielemann, T. Ressler, A. Walter, G. Tzolova-Müller, C. Hess Appl. Catal., A. 2011, 399, 2834.

[101] N. Kosinov, F. J. Coumans, G. Li, E. Uslamin, B. Mezari, A. S. Wijpkema, E. A. Pidko, E. J. Hensen J. Catal. 2017, 346, 125-133.

[102] W. Ding, G. D. Meitzner, E. Iglesia J. Catal. 2002, 206, 14-22.

[103] H.-Y. Chen, W. M. H. Sachtler Catal. Lett. 1998, 50, 125-130.

[104] B. R. Muller, G. Calzaferri J. Chem. Soc., Faraday Trans. 1996, 92, 1633-1637.

[105] Y. You-Sing, R. F. Howe J. Chem. Soc., J. Chem. Soc., Faraday Trans. 1 F. 1986, 82, 2887-2896.

[106] J. L. Zeng, Z. T. Xiong, H. B. Zhang, G. D. Lin, K. R. Tsai Catal. Lett. 1998, 53, 119-124.

[107] P. L. Tan, C. T. Au, S. Y. Lai Appl. Catal., A. 2007, 324, 36-41.

[108] S. Lai, Y. She, W. Zhan, Y. Guo, Y. Guo, L. Wang, G. Lu J. Mol. Catal. A: Chem. 2016, 424, 232-240.

[109] D. Ma, Y. Shu, X. Han, X. Liu, Y. Xu, X. Bao J. Phys. Chem. B. 2001, 105, 1786-1793.

[110] W. Zhang, D. Ma, X. Han, X. Liu, X. Bao, X. Guo, X. Wang J. Catal. 1999, 188, 393-402.

[111] M. Ding, H. Xiuwen, Z. Danhong, Y. Zhimin, F. Riqiang, X. Yide, B. Xinhe, H. Hongbing, A. -Y. S. C.

F. Chem. Eur. J. 2002, 8, 4557-4561.

[112] A. Martínez, E. Peris, M. Derewinski, A. Burkat-Dulak Catal. Today. 2011, 169, 75-84.

[113] Y. Shu, D. Ma, L. Xu, Y. Xu, X. Bao Catal. Lett. 2000, 70, 67-73.

[114] B. Rhimi, M. Mhamdi, V. N. Kalevaru, A. Martin RSC Adv. 2016, 6, 65866-65878.

[115] H. Liu, X. Bao, Y. Xu J. Catal. 2006, 239, 441-450.

[116] H. Liu, Y. Xu Chinese J. Catal. 2006, 27, 319-323.

[117] M. Nachtegaal, U. Hartfelder, J. A. van Bokhoven in From Spectator Species to Active Site Using

$X$-ray Absorption and Emission Spectroscopy Under Realistic Conditions, (Eds.: J. Frenken, I. Groot),

Springer International Publishing, Cham, 2017, pp.89-110.

[118] C. Lamberti, A. Zecchina, E. Groppo, S. Bordiga Chem. Soc. Rev. 2010, 39, 4951-5001.

[119] P. A. Crozier, T. W. Hansen MRS Bull. 2015, 40, 38-45.

[120] K. Yoshida, K. Toyoura, K. Matsunaga, A. Nakahira, H. Kurata, Y. H. Ikuhara, Y. Sasaki Sci. Rep.

2013, 3, 2457.

[121] P. Kumar, K. V. Agrawal, M. Tsapatsis, K. A. Mkhoyan Nat. Commun. 2015, 6, 7128.

[122] D. Ma, Y. Shu, W. Zhang, X. Han, Y. Xu, X. Bao Angew. Chem. Int. Ed. 2000, 39, 2928-2931.

[123] G. Doyen, G. Ertl Surf. Sci. 1974, 43, 197-229.

[124] N. Kosinov, F. J. A. G. Coumans, E. A. Uslamin, A. S. G. Wijpkema, B. Mezari, E. J. M. Hensen ACS Catal. 2017, 7, 520-529. 
[125] D. Soulivong, S. Norsic, M. Taoufik, C. Coperet, J. Thivolle-Cazat, S. Chakka, J.-M. Basset J. Am. Chem. Soc. 2008, 130, 5044-5045.

[126] F. Yin, G. Wang, M.-R. Li Phys. Chem. Chem. Phys. 2017.

[127] C. Li, M. Zheng, A. Wang, T. Zhang Energy Environ. Sci.. 2012, 5, 6383-6390.

[128] W. Wu, Z. Wu, C. Liang, P. Ying, Z. Feng, C. Li Phys. Chem. Chem. Phys. 2004, 6, 5603-5608.

[129] J.-S. Choi, J.-M. Krafft, A. Krzton, G. Djéga-Mariadassou Catal. Lett. 2002, 81, 175-180.

[130] C. Doornkamp, V. Ponec J. Mol. Catal. A: Chem. 2000, 162, 19-32.

[131] V. P. Santos, T. A. Wezendonk, J. J. D. Jaén, A. I. Dugulan, M. A. Nasalevich, H.-U. Islam, A.

Chojecki, S. Sartipi, X. Sun, A. A. Hakeem, A. C. J. Koeken, M. Ruitenbeek, T. Davidian, G. R. Meima, G. Sankar, F. Kapteijn, M. Makkee, J. Gascon Nat. Commun. 2015, 6.

[132] K. Xu, B. Sun, J. Lin, W. Wen, Y. Pei, S. Yan, M. Qiao, X. Zhang, B. Zong Nat. Commun. 2014, 5, 5783.

[133] V. V. Ordomsky, B. Legras, K. Cheng, S. Paul, A. Y. Khodakov Catal. Sci. Technol. 2015, 5, 14331437.

[134] D. Ma, Y. Shu, M. Cheng, Y. Xu, X. Bao J. Catal. 2000, 194, 105-114.

[135] E. G. Derouane, J. B. Nagy, P. Dejaifve, J. H. C. van Hooff, B. P. Spekman, J. C. Védrine, C.

Naccache J. Catal. 1978, 53, 40-55.

[136] P. Qiu, J. H. Lunsford, M. P. Rosynek Catal. Lett. 1998, 52, 37-42.

[137] A. Mehdad, R. F. Lobo Catal. Sci. Technol. 2017, 7, 3562-3572.

[138] P. Cnudde, K. De Wispelaere, J. Van der Mynsbrugge, M. Waroquier, V. Van Speybroeck J. Catal. 2017, 345, 53-69.

[139] M.-F. Hsieh, Y. Zhou, H. Thirumalai, L. C. Grabow, J. D. Rimer ChemCatChem. 2017, n/a-n/a. [140] V. R. Choudhary, P. Devadas, S. Banerjee, A. K. Kinage Microporous Mesoporous Mater. 2001, 47, 253-267.

[141] X. Chen, M. Dong, X. Niu, K. Wang, G. Chen, W. Fan, J. Wang, Z. Qin Chinese J. Catal. 2015, 36, 880-888.

[142] H. Coqueblin, A. Richard, D. Uzio, L. Pinard, Y. Pouilloux, F. Epron Catal. Today. 2017, 289, 62-69.

[143] R. Le Van Mao, L. A. Dufresne, J. Yao, Y. Yu Appl. Catal., A. 1997, 164, 81-89.

[144] P. Mériaudeau, V. T. T. Ha, L. V. Tiep Catal. Lett. 2000, 64, 49-51.

[145] X. Niu, J. Gao, Q. Miao, M. Dong, G. Wang, W. Fan, Z. Qin, J. Wang Microporous Mesoporous Mater. 2014, 197, 252-261.

[146] L. A. Dufresne, R. Le Van Mao Catal. Lett. 1994, 25, 371-383.

[147] M. Berthelot CR Acad. Sci. 1866, 62, 905.

[148] P. Tsai, J. R. Anderson J. Catal. 1983, 80, 207-214.

[149] W. Lee, T. Lee, H.-G. Jang, S. J. Cho, J. Choi, K.-S. Ha Catal. Today. 2018, 303, 177-184.

[150] P. Mériaudeau, L. V. Tiep, V. T. T. Ha, C. Naccache, G. Szabo J. Mol. Catal. A: Chem. 1999, 144, 469-471.

[151] Y. Schuurman, C. Mirodatos Appl. Catal., A. 1997, 151, 305-331.

[152] D. Zhou, S. Zuo, S. Xing J. Phys. Chem. C. 2012, 116, 4060-4070.

[153] X. Gao, Q. Xin J. Catal. 1994, 146, 306-309.

[154] F. Larkins, A. Khan Aust. J. Chem. 1989, 42, 1655-1670.

[155] I. Yarulina, A. D. Chowdhury, F. Meirer, B. M. Weckhuysen, J. Gascon Nat. Catal. 2018, 1, 398411.

[156] S. P. Yuan, J. G. Wang, Y. W. Li, H. Jiao J. Phys. Chem. A. 2002, 106, 8167-8172.

[157] I. L. C. Buurmans, B. M. Weckhuysen Nat. Chem. 2012, 4, 873-886.

[158] P. Schwach, X. Pan, X. Bao Chem. Rev. 2017, 117, 8497-8520.

[159] Y. Xiang, H. Wang, J. Cheng, J. Matsubu Cat. Sci, Technol,. 2018, 8, 1500-1516.

[160] N. Kosinov, A. S. G. Wijpkema, E. Uslamin, R. Rohling, F. J. A. G. Coumans, B. Mezari, A. Parastaev, A. S. Poryvaev, M. V. Fedin, E. A. Pidko, E. J. M. Hensen Angew. Chem. Int. Ed. 2018, 57, 1016-1020.

[161] I. Yarulina, A. Dutta Chowdhury, F. Meirer, B. M. Weckhuysen, J. Gascon Nat. Catal. 2018. 
[162] I. Yarulina, K. De Wispelaere, S. Bailleul, J. Goetze, M. Radersma, E. Abou-Hamad, I. Vollmer, M. Goesten, B. Mezari, E. J. M. Hensen, J. S. Martínez-Espín, M. Morten, S. Mitchell, J. Perez-Ramirez, U. Olsbye, B. M. Weckhuysen, V. Van Speybroeck, F. Kapteijn, J. Gascon Nat. Chem.. 2018.

[163] M. Guisnet, L. Costa, F. R. Ribeiro J. Mol. Catal. A: Chem. 2009, 305, 69-83.

[164] Y. Lu, D. Ma, Z. Xu, Z. Tian, X. Bao, L. Lin Chem. Commun. 2001, 2048-2049.

[165] M. J. Nash, A. M. Shough, D. W. Fickel, D. J. Doren, R. F. Lobo J. Am. Chem. Soc. 2008, 130, 2460-2462.

[166] H. E. Bergna in The colloid chemistry of silica, ACS, Washington, DC (United States), 1994.

[167] P. L. J. Gunter, J. W. Niemantsverdriet, F. H. Ribeiro, G. A. Somorjai Catal. Rev. 1997, 39, 77-168.

[168] D. Ma, Q. Zhu, Z. Wu, D. Zhou, Y. Shu, Q. Xin, Y. Xu, X. Bao Phys. Chem. Chem. Phys. 2005, 7, 3102-3109.

[169] J. Guo, H. Lou, X. Zheng J. Nat. Gas Chem. 2009, 18, 260-272.

[170] T. Liang, J. Chen, Z. Qin, J. Li, P. Wang, S. Wang, G. Wang, M. Dong, W. Fan, J. Wang ACS Catal. 2016, 6, 7311-7325.

[171] G. Sastre, A. Corma J. Mol. Catal. A: Chem. 2009, 305, 3-7.

[172] D. Lesthaeghe, V. Van Speybroeck, M. Waroquier Phys. Chem. Chem. Phys. 2009, 11, 5222-5226.

[173] N. Kosinov, E. J. M. Hensen in Nonoxidative Dehydroaromatization of Methane, Wiley, 2017, 469 - 481.

[174] C.-L. Zhang, S. Li, Y. Yuan, W.-X. Zhang, T.-H. Wu, L.-W. Lin Catal. Lett. 1998, 56, 207-213.

[175] S.-T. Wong, Y. Xu, W. Liu, L. Wang, X. Guo Appl. Catal., A. 1996, 136, 7-17.

[176] K. Sun, D. M. Ginosar, T. He, Y. Zhang, M. Fan, R. Chen Ind. Eng. Chem. Res. 2018, 57, 1768-1789.

[177] H. Liu, S. Wu, Y. Guo, F. Shang, X. Yu, Y. Ma, C. Xu, J. Guan, Q. Kan Fuel. 2011, 90, 1515-1521.

[178] H. Liu, S. Yang, S. Wu, F. Shang, X. Yu, C. Xu, J. Guan, Q. Kan Energy. 2011, 36, 1582-1589.

[179] C. Xu, J. Guan, S. Wu, M. Jia, T. Wu, Q. Kan Reaction Kinetics, Mechanisms and Catalysis. 2010, 99, 193-199.

[180] A. Martínez, E. Peris, G. Sastre Catal. Today. 2005, 107-108, 676-684.

[181] J. Bai, S. Liu, S. Xie, L. Xu, L. Lin Catal. Lett. 2003, 90, 123-130.

[182] X. Guo, G. Fang, G. Li, H. Ma, H. Fan, L. Yu, C. Ma, X. Wu, D. Deng, M. Wei, D. Tan, R. Si, S. Zhang, J. Li, L. Sun, Z. Tang, X. Pan, X. Bao Science. 2014, 344, 616-619.

[183] F. Solymosi, A. Szoke in Study of the reactions of ethylene on supported Mo2C/ZSM-5 catalyst in relation to the aromatization of methane, Vol. 119, 1998, 355-360.

[184] N. Kosinov, F. J. A. G. Coumans, E. A. Uslamin, A. S. G. Wijpkema, B. Mezari, E. J. M. Hensen ACS Catal. 2016, 520-529.

[185] K. D. Campbell, E. Morales, J. H. Lunsford J. Am. Chem. Soc. 1987, 109, 7900-7901.

[186] T. Ito, J. Wang, C. H. Lin, J. H. Lunsford J. Am. Chem. Soc. 1985, 107, 5062-5068.

[187] L. L. Iaccino, T. Xu, J. S. Buchanan, N. Sangar, J. J. Patt, M. A. Nierode, K. R. Clem, M. Afeworki in Production of aromatics from methane, Google Patents, 2009. 